\title{
A Emergência da cena cosplay nas culturas juvenis $^{1}$
}

////////////I Monica Rebecca Ferrari Nunes ${ }^{2}$

1. Trabalho apresentado ao GT Comunicação e Cultura do XXII Encontro Anual da Compós, na Universidade Federal da Bahia, Salvador, de 04 a 07 de junho de 2013. Este artigo integra a Pesquisa Comunicação, Consumo e Memória: Cosplay e Culturas Juvenis, com apoio do CNPq (Chamada MCTI/CNPq/MEC/CAPES N. 18/2012 Ciências Humanas, Sociais e Sociais Aplicadas) em desenvolvimento junto ao PPGCOM-ESPM.

2. Doutora em Comunicação e Semiótica (PUCSP). Docente e Pesquisadora do PPGCOM-ESPM. Pesquisadora do CNPq. Coordenadora da Linha de Pesquisa em Comunicação, consumo e memória, vinculada ao Grupo de Pesquisa em Comunicação, consumo e entretenimento (CNPq/PPGCOMESPM). E-mail: monicarfnunes@ espm.br. 
Resumo Com base na teoria semiótica da cultura de Tártu-Moscou e em estudos sobre consumo, este paper analisa a cena cosplay e os aspectos da semiosfera na emergência desta cena, considerando-a como prática cultural, de significação e sociabilidade em que jovens se vestem e atuam como personagens de narrativas midiáticas. $\mathrm{O}$ artigo traz os resultados parciais da pesquisa de campo, em eventos de cultura pop, entre 2012 e 2013, investigando as relações cosplay-cosplayer.

Palavras-chave Cena Cosplay, semiosfera, consumo, cultura juvenil.

Abstract Based on the Semiotics theory of Culture, by Tartu-Moscow School, and on consumption theories, this paper analyses the cosplay scene configuration and the aspects of the semiosphere in the emergence of this scenario, considered as a cultural practice, a practice of significance and sociability, where youth people dress and act as characters of media narratives. This paper shows partial results of a field research carried out in 2012 and 2013 in events of pop culture. It focuses the relationship between cosplayer-cosplay.

Keywords Cosplay scene, semiosphere, consumption, youth culture. 
3. A pesquisa de campo do Anime Dreams 2013 ocorreu durante os três dias do evento, 25,26 e 27 de janeiro de 2013 , entre às $11 \mathrm{~h} 30$ e $18 \mathrm{~h} 00$. Foram coletados 27 depoimentos em vídeo e dois impressos, totalizando

29 entrevistas; também foram produzidas 40 imagens fotográficas.

Neste paper, os depoimentos são articulados aos resultados da primeira parte da pesquisa, transcorrida em 2012, sem fomento do CNPq.

Naquela etapa foram cartografados

três eventos: Anime Dreams 2012 (janeiro, Universidade Cruzeiro do Sul, São Paulo, SP) resultando em 19 entrevistas; Anime Party 2012 (março,

Faculdade Cantareira, São Paulo,

$\mathrm{SP})$ resultando em 18 entrevistas e Anime Friends 2012 (julho, Faculdade Cantareira, São Paulo, SP) resultando

em 26 entrevistas. Vale dizer que a pesquisa é qualitativa e se caracteriza por entrevistas em profundidade.

4. Informações disponíveis em $<$ http://www.animedreams.com.br/c ycc.shtml>. Acesso em 11 fev. 2013. A dinâmica destes concursos não será analisada neste trabalho.

\section{Introdução}

Janeiro abafado e chuvoso. Ladeiras íngremes circundam os muros do Colégio Marista Glória, sede do festival Anime Dreams 2013, um dos eventos cartografados por esta pesquisa. O encontro é realizado pela Yamato Comunicações e Eventos, instalada na metrópole paulista. O cansaço já toma conta dos cosplayers e de mim mesma, contaminada pelos relatos, pela densa paisagem visual e sonora: cabelos azuis, espetados, personagens de tantos mundos, vozes e músicas em alto volume. Em uma coxia improvisada, termino as entrevistas ${ }^{3}$ e tomo o depoimento de alguns dos finalistas do concurso YCC, Yamato Cosplay Cup, realizado durante a convenção.

Criado em 2007 pela empresa Yamato, estes concursos reúnem participantes de várias regiões do país avaliados em três categorias: cos-desfile, importando a fidelidade do traje; play-tradicional, em que a roupa da personagem e a encenação de um trecho da narrativa original são apreciadas, e play-livre, modalidade que prevê a criação de uma cena em que a personagem desenvolva uma situação inusitada. ${ }^{4}$ Mochilas espalhadas, refrigerantes sobre uma pequena mesa, jovens recostados, alguns sentados no chão, outros sem maquiagem, peruca e máscara. Esperam o resultado da dupla vencedora enquanto desmontam seus cenários e suas criações, os cosplays, boa parte deles confeccionados pelos próprios jovens.

Não há ainda uma historiografia consolidada sobre o cosplay. Existem dados esparsos, dispersos em sites não acadêmicos que apontam as convenções de filmes de ficção científica surgidas nos EUA, em final da década de 1930, como sua origem, pois, naqueles festivais, fãs se vestiam como personagens fílmicos. Esta atividade 
5. Disponível <http://www.cosplaybr. com.br/site/index.php/O-Que-eCosplay.html>. Acesso em 18 nov.

2012.

6. Disponível em <http://www. cosplayers.net/pt/eventos/details/322bakudan.html>. Acesso em 21 jan. 2013.

7. Pesquisa de campo realizada durante o Anime Dreams 2012 nos dias 13, 14 e 15 de janeiro de 2013. A entrevista de Reinaldo foi coletada em 14 de janeiro de 2012, na Universidade Cruzeiro do Sul, São

Paulo, SP.

8. Beatriz foi entrevistada durante o Anime Dreams 2013 em 27 de janeiro no Colégio Marista Glória, São Paulo, SP. teria se tornado comum e gerado concursos de fantasias denominados masquerades, em que os fantasiados poderiam representar um extrato do filme.

No Japão, durante a década de 1980, o jornalista Nobuyuki Takahashi publicou inúmeras matérias sobre o assunto, denominando por cosplay, contração de costume play, ${ }^{5}$ o ato de se vestir como personagens. Logo, a prática tornou-se bastante expressiva entre os jovens de Tóquio, entretanto, não mais trajando os costumes das personagens de filmes de ficção, mas aquelas dos mangás, animês e tokusatsus, filmes de ação que congregam monstros e heróis (LUYTEN, 2005).

No Brasil, o uso do cosplay afirma-se ao final dos anos 1990 (AMARAL e DUARTE, 2008; COELHO JR. e SILVA, 2007), juntamente com o surgimento, na cultura jovem urbana, dos festivais de animês, um dos espaços de congraçamento de cosplayers. Hoje estes eventos de entretenimento estão enraizados nos centros do país, de norte a sul - a exemplo do Amapá Anime, Macapá; Otaku no Matsuri, Belém do Pará; Sana Fest, em Fortaleza; Nippop, em Vitória; Circuito Gaúcho de Cosplay, entre outros ${ }^{6}$.

As convenções oferecem inúmeras atrações como os concursos de cosplay, apresentações de bandas de animês, concursos de animekês (karaokê de trilhas sonoras de animês) salas temáticas voltadas a produtos culturais consumidos pelo público jovem, constituindo-se em verdadeiras salas da memória ao atualizarem as personagens e narrativas midiáticas: salas de ficções televisivas e cinematográficas, tokusatsus, cards, videogames, objetos e atividades medievais; exposições de mangás, fanzines, quadrinhos, e contam com espaços onde estandes de empresas comercializam toda sorte de mercadorias referentes à cultura pop.

Os cosplayers também frequentam certas praças da cidade de São Paulo, como as do bairro da Liberdade, com forte tradição oriental; reuniões caseiras em que realizam ensaios fotográficos, conforme o relato de Reinaldo, ${ }^{7} 25$ anos, que vê no cosplay uma forma de passar o tempo e de se divertir; festas universitárias, segundo o depoimento de Beatriz ${ }^{8}$, de 19 anos, estudante de jornalismo da Faculdade de Comunicação e Artes de Salto, interior do estado de São Paulo. Vestida como Gata Negra, explica o projeto que desenvolveu, com amigas, para que as festas da faculdade incorporassem os cosplays, já 
que na região não existem eventos organizados como os de São Paulo ou de Sorocaba, cidade mais perto de onde mora. De igual maneira, encontram-se cosplayers nas filas de vultosas estreias cinematográficas tais quais as séries Harry Potter e Crepúsculo/Amanhecer ou, ainda, em shows de rock e música pop.

Para compreender a inserção deste fenômeno nos espaços urbanos, o conceito de cena (STRAW, 2004) parece oportuno ao esclarecer como as práticas articulam um sentido ao espaço, por sua vez, transformado "em lugares de cena através da espetacularização de narrativas e de ações” (HERSHMANN, 2012, p.9). Assim fazem os cosplayers, não importando o espaço geográfico em si mesmo. Segundo Straw, a cena refere-se à esfera circunscrita de sociabilidade, criatividade e conexão que toma forma em torno de certos tipos de objetos culturais no transcurso da vida social destes objetos (STRAW apud JANOTTI, 2012). Pode-se considerar a cena referindo-se a um sentido amplo de teatralidade pública (BLUM, 2003), e a trajetórias de circulação, ampliando a complexidade da cultura urbana.

Com base neste conceito e nos resultados da pesquisa de campo em andamento, denomino a prática cosplay também como cena. Considerando-a como trajetória de circulação de textos culturais, na acepção dos semioticistas de Tártu-Moscou, observada mais adiante, especialmente, narrativas, personagens, atores sociais e circulações de sentidos. A cena cosplay revela modos de exercitar a teatralidade pública adensada pelas emoções proporcionadas pelas narrativas midiáticas em sua interface comunicação e consumo. Determinantes para a construção de vínculos entre público e mídia. Fundamentais para o entendimento dos nexos entre cosplayercosplay, e entre os membros da própria comunidade cosplay imersa na cultura jovem.

Assim como no Brasil a quantidade de eventos e de possibilidades para esta prática cultural aumentou, as fontes de montagem para os cosplays também cresceram: os signos da cultura pop japonesa, personagens de mangás, animês, tokusatsus, games, convivem com outras narrativas e nacionalidades. Celebridades musicais, como Lady

9. Lincon, 19 anos com cosplay de Psy. Entrevistado no Anime Dreams 2013 em 26 de janeiro no Colégio Marista Glória, São Paulo, SP. Gaga e Psy ${ }^{9}$ - cantor sul-coreano, performer da música Gangnam Style; fenômenos editoriais, tal qual Harry Potter; personagens de séries televisivas, como a britânica Doctor Who, a estadunidense The Walking Dead, ou mesmo aquelas do cenário empresarial, a 
10. Fabrício fez cosplay de Ronald McDonald no Anime Friends 2012 e foi entrevistado em 05 de julho de 2012 na Faculdade Cantareira, São Paulo, SP. exemplo de Ronald McDonald ${ }^{10}$, somam-se às criações da Disney ou da Marvel. Uma rede complexa de personagens vindos da cultura das mídias e da cibercultura, de variados gêneros e de cortes temporais distintos - e não somente as contemporâneas - inspiram os cosplayers, mesmo aquelas nem tão amáveis como Fred Krueger ou seres assustadores como o Tiranossauro Rex, de Jurassic Park.

O problema central da pesquisa é justamente investigar como os fãs habitam e consomem as memórias dos textos culturais que tenham gerado o desejo pelo cosplay. Na fase atual, analiso as características dos laços estabelecidos entre cosplayer-cosplay. Este trabalho procura, ainda que parcialmente, responder a estas inquietações contando com os referenciais teóricos sobre cultura juvenil e consumo e os da semiótica da cultura de Tártu-Moscou articulados à análise do material empírico especificados nas seções abaixo.

\section{Culturas juvenis e cena cosplay}

Ainda que brevemente, recupero o processo histórico que tornou possível a visibilidade dos jovens na última metade do século XX, e que fundamenta a emergência da cena cosplay inserida nas culturas juvenis urbanas. Rossana Reguillo (2012, p.19-38) contextualiza a juventude, tal qual conhecemos hoje, como uma invenção do pós-guerra, referindo-se à ordem internacional que trouxe, aos vencedores, substanciais vantagens econômicas e novos padrões de vida. Naquele período, uma poderosa indústria cultural oferecia, pela primeira vez, bens exclusivos para o consumo dos jovens que se tornaram sujeitos de direito, separados dos adultos no plano jurídico, e sujeitos de consumo (REGUILLO, 2012).

Estes jovens protagonizaram a revolução cultural vivida, especialmente no Ocidente, a partir dos anos 60, conforme expressa Eric Hobsbawm (2009, p.322): “a cultura jovem tornouse a matriz da revolução cultural no sentido mais amplo de uma revolução nos modos e costumes, nos meios de gozar o lazer e nas artes comerciais [...]". O historiador reconhece três novidades criadas pela cultura juvenil entremeada às sociedades urbanizadas: ser jovem não é mais entendido como um estágio preparatório para a vida adulta, mas sim, o ápice do desenvolvimento; torna- 
se dominante nas economias de mercado bem-sucedidas e se internacionaliza.

Porém, a existência de uma cultura jovem global, difundida por meio da indústria fonográfica, da moda, da indústria do entretenimento, enfim, não contraria o fato de compreendermos os jovens como categoria fundamentalmente heterogênea. As culturas juvenis têm um caráter descontínuo e dinâmico e há muitos modos de ser jovem e de estar junto, parafraseando Martín-Barbero (apud REGUILLO, 2012, p.33).

Para a antropóloga mexicana, os contornos imprecisos do sujeito e suas práticas culturais e comunicativas transformam-se em lugares metodológicos a partir dos quais se interroga a realidade. De tal forma, conduzir metodologicamente a análise sobre como os jovens cosplayers se relacionam com seus cosplays, evidenciando os processos envolvidos no ato de selecionar uma personagem para representá-la a partir do entendimento do fazer cosplay como prática cultural, não privilegiando uma identidade grupal, permite inquirir este coletivo e averiguar, entre outros elementos desta cena, os trânsitos interculturais e midiáticos exibidos para a montagem dos indumentos.

Personagens e narrativas midiáticas tornam-se referentes por meio dos quais se podem rastrear os usos de materialidades e os modos de consumir que instauram sentidos para estes jovens. O entendimento do modo de estar junto através das práticas permite compreender os variados papéis que estes sujeitos assumem, modos de produção de subjetividade assim como as formas de interações socioculturais que realizam.

Por conseguinte, a pesquisa se liberta do imperativo territorial que condicionou muitos trabalhos sobre juventude, vinculando as vivências das ruas como geradoras de atores juvenis dissidentes ou alternativos, e, por outro lado, as experimentações de espaços institucionais propulsoras de atores incorporados ao status quo (REGUILLO, 2012). Em outro artigo (NUNES, 2012a), pude perceber que o fato dos encontros de cosplayers pesquisados acontecerem sob a organização de uma grande empresa como a Yamato não atomiza o espírito lúdico de seus partícipes, ainda que este espaço seja controlado: revistas à entrada, ausência de bebidas alcoólicas e normas rígidas de segurança. Muitos jovens enxergam 
11. Iuri e Rafaella. Entrevistados em 27 de janeiro de 2013 durante o Anime Dreams 2013, no Colégio Marista Glória, São Paulo, SP.

12. Jacqueline. Entrevistada em 26 de janeiro de 2013 no Anime Dreams 2013, no Colégio Marista Glória. São Paulo, SP. nesta prática modos de resistência, ainda que uma resistência “'plural, diversa, polimorfa', vinculada a experiências de relativização de identidades e de recusas das formas 'normais' ou convencionais de comunicação e relacionamentos sociais cotidianos" (FREIRE FILHO, 2007, p.52).

Diante disso, compreender as práticas e seus sujeitos torna possível enfraquecer igualmente o imperativo das identidades essencialistas. Fazer cosplay, ser um cosplayer não impede que estes jovens exercitem outros investimentos identitários. Iuri Laudrup, cosplayer há nove anos, e Rafaella ${ }^{11}$, há seis participando de eventos, ganharam a seletiva Amapá Anime, em Macapá, com o cosplay de Tiranossauro Rex, que eles mesmos construíram com papel machê; vieram a São Paulo para a final da competição do YCC. Iuri escreve contos e vai se mudar do estado onde vive para conseguir mais chances para ser um escritor: "em Macapá não tem nem editora e as gráficas só imprimem material de políticos", comenta em meio à entrevista. Rafaella está se formando em Biologia, "nada a ver com esse mundo de arte, de cosplay", afirma a jovem, embora ambos integrem um Grupo Independente de Cosplay, grupo de teatro que reúne vinte amigos em Macapá. Realizam peças teatrais interpretando animês ou qualquer outra narrativa fílmica.

Diferentemente de Iuri que quer ser escritor, mas aprecia se fantasiar desde criança, ou mesmo de Rafaella, formanda em Biologia, contudo atriz de um grupo de teatro amador - o que imprime maior proximidade ao universo cosplay - Jacqueline ${ }^{12}, 20$ anos, cosplayer desde 2010 e também concorrente do YCC, ilustra um relato singular: este ano passou no vestibular para Engenharia na Universidade Federal do ABC, "o que sempre quis: fazer Engenharia em uma universidade pública”; a garota escolhe o cosplay por meio de critérios variados, inclusive o de não gostar da personagem contrariando a grande maioria dos depoimentos colhidos até então que, com regularidade, apresenta como primeiro motivo para a escolha do traje o afeto pela personagem. A que foi selecionada por Jacqueline, Midna, do jogo A lenda de Zelda Twilight Princess - "tem uma fala eletrônica e não tem expressão”. A seleção deu-se graças ao desafio da própria indumentária. Caso diverso de Iuri, "que, desde criança, sempre quis ver um dinossauro, mostrar um dinossauro pros outros" -- diz ao contar os motivos de sua escolha. Este tipo de relato é comum entre os jovens pesquisados que reconhecem no 


\section{A Emergência da cena cosplay nas culturas juvenis | Monica Rebecca Ferrari Nunes}

13. Osmar. Entrevistado no Anime Dreams 2013 em 25 de janeiro de 2013. Colégio Marista Glória. São Paulo, SP.

14. Alan. Entrevistado no Anime Dreams 2012 no dia 15 de janeiro. Faculdades Cantareira. São Paulo, SP.

15. Entrevista realizada em 26 de janeiro durante o evento Anime Dreams 2013, no Colégio Marista Glória, São Paulo, SP. fazer cosplay um modo de compartilhar com outras pessoas suas personagens preferidas.

Osmar $^{13}$, 27 anos, também revela modos diversos de ser cosplayer. Traz informações não verificadas em outros depoimentos: começou a fazer cosplay de super Mario Bros na São Silvestre, maratona que ocorre na cidade de São Paulo na passagem de ano-novo. "[...] Pensei: um dia vou num evento de Mario [...] isso desde 2007, e, até hoje, eu só faço cosplay dele, só que eu faço várias versões". Explica que em cada game o personagem exibe variações em suas roupas e acessórios e, por isso, procura as versões "mais obscuras possíveis", porque o objetivo deste jovem é se diferenciar dos demais que selecionam o pequeno herói italiano com bastante frequência.

Não é possível reconhecer um jeito único de ser cosplayer ou de fazer cosplay. Alan ${ }^{14}$ não tem ascendência oriental, mas foi educado em meio a estas tradições, entretanto, não aprecia "tanto assim" J-pop/ J-rock ou K-pop/K-rock, estilos musicais japoneses ou coreanos bastante consumidos nestes eventos e entre estes jovens - mas gosta e escuta metal finlandês. Beatriz, a estudante de jornalismo, já mencionada, prefere se vestir como personagens de HQs estadunidenses e não de animês. Os exemplos proliferam. Desnecessário arrolar todos eles.

O hibridismo na composição de preferências, pertencimentos e identificações verificados pela pesquisa de campo demonstra o diálogo desta cena com estudos contemporâneos sobre culturas juvenis que atestam a heterogeneidade e os modos diversos de estar junto - considerando a mesma cena. Verifica-se aqui as "dilatações juvenis", nas palavras de Canevacci (2005, p.29), designadas para reconhecer que, em nossos tempos, "cada indivíduo pode perceber sua condição de jovem como não-terminada e inclusive como nãoterminável". Ainda que o público, especialmente dos eventos, gire em torno de 13 a 30 anos, é bastante comum encontrarmos jovens adultos, pais e filhos vestidos como seus personagens de afeto ou senão, portando algum acessório da personagem, e, conforme o depoimento de Elder, ${ }^{15}$ coordenador de atrações da Yamato, até mesmo pessoas de 60 e 70 anos competem nos concursos culturais.

A cena cosplay não diz respeito apenas aos concursos, à flânerie dos participantes, às salas temáticas e aos produtos vendidos como forma de materialização e consumo da memória midiática coletiva, ainda que efemeramente. A cena congrega outras teatralidades. 
16. Kakao foi entrevista em 15 de janeiro durante o Anime Dreams 2012, na Universidade Cruzeiro do Sul, São Paulo, SP.

17. "O kawaii contemporâneo surge na década de 1970 (...) É agora, essencialmente, uma estética

que encontra a beleza em coisas frágeis, imaturas, inocentes e puras combinadas com a necessidade de proteção dos adultos. O kawaii é traduzido em inglês como cute, lovely ou pretty" (OKANO, 2012).

Disponível em <http://www. jornalmemai.com.br/tag/michikookano>. Acesso em 18 de nov.2012.

18. Entrevista realizada em 15 de janeiro de 2012. A discussão sobre as cenas envolvendo música e moda não será desenvolvida aqui.
Música (NUNES, 2012b) e moda urbana japonesa, por sua vez, representadas pelas lolitas e fairies, formam novas cenas em diálogo contínuo nestes espaços produtores de sentidos. O estilo fairy kei foi explicado por Kakao que trajava este look no evento Anime Dreams 2012: "uma coisa Ursinhos Carinhosos, Meu Querido Pônei, mais contos de fadas, mas que pega uma vibe anos 80" (Kakao $\left.{ }^{16}\right)$. Já o estilo lolita tem bases da estética kawaii ${ }^{17}$ identificada por meio dos tons de rosa, tecidos florais e rendas, somados aos traços vitorianos e rococós dos vestidos conferindo às jovens “o jeito de menina”, conforme o relato de Akemi, entrevistada no evento Anime Dreams 2012 ${ }^{18}$.

\section{Aspectos da Semiosfera na Cena Cosplay}

Ao evidenciar a descrição da cena cosplay, seus sujeitos e os modos de seleção operados, sublinho a própria complexidade e a emergência de uma prática comunicativa e de sociabilidade que traz marcas sígnicas de configurações mais genéricas das culturas juvenis atuais. Sem pretender resenhar os principais conceitos da obra de Iúri Lotman - tarefa já realizada por estudiosos e comentadores de sua obra (SCHNAIDERMAN, 1979; PIRES-FERREIRA, 1989; MACHADO, 2003, 2007, entre outros) - julgo importante trazer à luz algumas postulações teóricas para a apreciação da cena cosplay, objetivando cartografar os modos de vinculação desenvolvidos pelos jovens para habitarem as memórias de narrativas e personagens ressurgidos nos indumentos.

Compreende-se esta cena como prática que se vale de inúmeros sistemas sígnicos. Como profere o pensador de Tártu, não existem sistemas trabalhando sozinhos, "funcionam submersos em um continuum semiótico, completamente ocupado por formações semióticas de diversos tipos e que se comunicam em diversos níveis de organização" (LOTMAN, 1996, p. 22).

Sabe-se que este continuum foi denominado semiosfera: espaço abstrato, mas não metafórico, onde vivem os signos na cultura; espaço semiótico em que se produzem os processos comunicativos e novas informações e fora do qual não há semiose, ação do signo. No entender de Machado (2007, p.16), "semiosfera é o conceito que se constitui para nomear e definir a dinâmica dos encontros entre 
19. Entrevistado em 27 de janeiro no Anime Dreams 2013 no Colégio Marista Glória, São Paulo, SP. diferentes culturas e, assim, construir uma teoria crítica da cultura”. Se bem que a historiografia do cosplay esteja ainda sendo traçada, sua origem refere-se às ligações entre sistemas culturais e sígnicos distintos: o cinema de ficção científica gerando as masquerades, nos EUA, os mangás, tokusatsus e animês inspirando o cosplay, no Japão, a chegada ao Brasil, congregando variegadas fontes narrativas e outros modos de praticá-lo, como explica o responsável pelo núcleo de atrações da Yamato, ao enfatizar que o cosplay livre - categoria observada nos desfiles - nos quais o cosplayer inventa uma situação nunca vivida pela personagem, só existe no Brasil:

O Brasil criou um próprio modo para o cosplay. Cada país tem regras diferentes, na Rússia, por exemplo, a apresentação [do cosplayer em uma cena da narrativa de onde foi extraída a personagem] é uma coisa que eles não têm costume de fazer, o desfile é uma coisa grande, as pessoas não pegam em um microfone para falar; aqui no Brasil, as pessoas gostam de encenar [...] lá fora não existe a categoria livre que nós temos aqui [...] (Elder, coordenador de atrações da Yamato) $)^{19}$.

Lotman (1996, 1998) define a cultura, isto é, a semiosfera, como semioticamente não-homogênea, composta pela diversidade de sistemas sígnicos que modelizam os textos: texto cultural com funções de comunicação, de geração de sentido e de memória, porque o texto condensa informações, não só recebe informações de fora dele, mas também as ocasiona, e, assim, adquire memória. $\mathrm{Na}$ heterogeneidade da semiosfera, o intercâmbio entre os diferentes textos pode ser concebido como dialógico. E é neste trânsito que ocorrem as confluências imprevisíveis, criando novas organizações de linguagem, novos textos de cultura, a exemplo do cosplay - que igualmente condensa, em sua materialidade: trajes e acessórios, a memória de textos passados; suas personagens como vestígios metonímicos das narrativas de mangás, tokusatsus, animês, games e filmes; HQs estadunidenses ou possíveis textos culturais midiáticos ainda não modelizados.

Tal como o diálogo, a assimetria é um mecanismo da cultura que diz respeito a esta circulação de textos, ao traslado de um sistema de codificação a outro. Lotman (1996) inculca: 


\begin{abstract}
Análogo em seus fundamentos é o processo do trato entre culturas nos casos em que uma cultura recém-surgida tropeça com uma velha cultura. A reserva de textos, códigos e distintos signos que se precipita da velha cultura à cultura nova, mais jovem [...] depositam-se na memória cultural da coletividade como um valor autossuficiente (LOTMAN, 1996, p. 57).
\end{abstract}

Pensar a cena cosplay com base nestes fundamentos significa conhecer os deslocamentos midiáticos que garantem a transmissão dos textos, códigos e signos de uma velha cultura, nas palavras de Lotman, para uma cultura mais jovem, aqui representada pela a cena cosplay. Das culturas mais arcaicas, de tradição oral, brotam as fontes de textos mitológicos fundidos com documentos históricos e com a ficção narrativa achados em muitos mangás (BARBOSA, 2005). A oralidade, as narrativas míticas e os traços pictóricos dos quadrinhos japoneses continuam sobrevivendo nos animês, por sua vez, adaptados dos mangás para a linguagem audiovisual - televisão, cinema, vídeo ou internet, atentando ao fato de que muitos animês também são adaptados para mangás (LUYTEN, 2005). Reconhecese aqui um processo memético de transmissão midiática como já demonstrei no tocante à memória na mídia (NUNES, 2001), aproximando-se ao que Iúri Lotman expressa sobre a função mnésica dos textos da cultura:

A capacidade que têm distintos textos que chegam até nós da profundidade do passado cultural, de reconstruir camadas inteiras da cultura, de restaurar a recordação, é demonstrada por toda a história da humanidade. Não só metaforicamente poderíamos comparar os textos com as sementes das plantas, capazes de conservar e reproduzir a recordação de estruturas precedentes. (LOTMAN, 1996, p.89).

Interessante notar que a capacidade que os textos comportam para chegarem até nós vindos do passado deve-se a outro atributo: a longevidade de textos e de códigos, que corresponde à continuidade da própria memória. Os textos longevos são aqueles válidos segundo critérios de cada cultura. Por sua vez, a longevidade dos códigos deve-se “à sua capacidade de mudar conservando ao mesmo tempo 
20. Diego. Entrevistado no Anime Dreams 2013, no dia 27 de janeiro, no Colégio Marista Glória, São Paulo, a memória de seus estados precedentes" (LOTMAN e USPENSKII, 1981, p. 43). Vale esclarecer que estes conceitos não respondem apenas à transmissão cultural entre textos orais e míticos, mangás e animês, mas, como fundamentos de uma teoria geral que afirma a cultura como memória (LOTMAN e USPENSKII, 1981), aplica-se ao entendimento de como cosplayers habitam a memória, sobretudo midiática, acionada pelos coletivos juvenis envolvidos na cena cosplay.

Como texto complexo, plurivocálico, tecido por sistemas de códigos diferentes, condensador de memória e criador de novos textos, o cosplay assegura o poliglotismo desta semiosfera por intermédio de um tríplice processo de mediação. Considerando a Teoria da Mídia, sistematizada por Harry Pross, "que propõe os estudos da comunicação a partir de uma tripla tipologia dos processos de mediação: meios primários, os meios secundários e os meios terciários" (BAITELLO JÚNIOR, 2010, p.61), verifica-se que a realização do cosplay torna o corpo-mídia primária e multiplataforma do cosplayer o lugar para o qual se convertem as mídias secundárias, os textos impressos e, terciárias, os audiovisuais, ressignificando narrativas e personagens.

Diego $^{20}$ tem 22 anos, assiste aos animês na televisão desde criança, participava dos eventos apenas para se divertir. Conta que após conhecer Jacqueline - já citada aqui - decidiu competir com o cosplay de Link, guerreiro medieval, personagem do game A Lenda de Zelda Twilight Princess. Pergunto-lhe sobre o modo de fazer sua roupa. Mostra os detalhes para a câmera enquanto narra que fez o cosplay junto com a mãe, "tiramos o molde e fomos melhorando, fazendo mais detalhes [...]". Explica que tem três bons trajes, usa cada um deles dependendo do evento e do clima: "uma roupa do cavaleiro de Pégasus, que é cheio de espinho e armadura...no calor, com ela, é arriscado você passar mal [..].” Pensa também no tipo de evento em que utiliza o traje, "pois a roupa é frágil e pode quebrar". Diego e a mãe basearam-se em imagens extraídas da internet, "do personagem de frente, de lado". Para as competições, os cosplays devem ser fiéis, mas este jovem busca um sinal de diferenciação. Ele afirma: "eu costumo fazer [o cosplay] o mais próximo possível, mas com algum diferencial próprio" e me mostra a manga da roupa do cavaleiro Link com a borda "um pouquinho diferente" por causa da malha especial para manga e das franjas de tule. "São saídas estratégicas que eu utilizei e conforme você vai aprendendo com outros cosplayers você modifica sua própria roupa", conclui. 
21. Diego. Entrevistado no Anime Dreams 2013, no dia 27 de janeiro, no Colégio Marista Glória, São Paulo,

SP
22. Diego. Entrevistado no Anime

Dreams 2013, no dia 27 de janeiro, no Colégio Marista Glória, São Paulo,
A elaboração do cosplay mostra a ressignificação da personagem envolvida na escolha. A memória de outros cosplayers, criadores de outros cosplays, modifica mais uma vez a personagem-fonte mesmo tendo servido de modelo para a costura. O depoimento de Diego corrobora muitos outros. Arrolo mais dois, a título de fechamento desta seção. Verônica ${ }^{21}$ está com as amigas, vem da cidade de Tatuí, interior do estado de São Paulo. Vestida como Loki, o vilão da Marvel, comenta sobre os vários critérios para sua escolha: a personagem deve promover alguma identificação; a própria história; a disponibilidade dos materiais; o seu porte físico e a da personagem em questão. Apaixonada por HQs, usa a versão adolescente de Loki montada a partir de antigas versões impressas. No corpo da cosplayer, todos os Lokis convivem, revificados, em suas diversas idades.

Quando olhei para Clara ${ }^{22}$, imaginei uma personagem saída de Hogwarts, o castelo de Harry Potter, mas descubro Doctor Who no corpo de uma moça de 19 anos vestida com o casaco que pertenceu à sua bisavó. A jovem nunca usa peruca, mas adora "zoar" os próprios cabelos imprimindo também sua marca nos personagens que deseja fazer. Cabelos de todas as cores e cortes, túnicas, capacetes, escudos, pelúcias e uma série interminável de materiais revelam as codificações das culturas envolvidas nesta cena e seus sistemas sígnicos cartografando modos de consumir a memória de textos narrativos midiáticos.

Penso que o consumo afetivo, material e midiático, descortinado na cena cosplay, funciona como código cultural, no sentido de Tártu-Moscou, inaugurando novas sensibilidades e entendimentos, valendo-se do fato do consumo ser também um fenômeno sensorial e cognitivo conforme defende Rose Rocha (2008). Os cosplayers, imprimindo suas marcas, provocam rupturas e ressignificações de narrativas e personagens hegemônicas uma vez recriadas graças ao EVA, à madeira, a materiais nobres ou não.

Entretanto, sabe-se que o jogo do consumo também hierarquiza, exclui, classifica (SLATER, 2002): os termos cospobre e cosplay surgem como oposições binárias que definem intencionalidades - apenas brincar, conforme os relatos dos que não participam dos desfiles e não demonstram tanta preocupação com a fidelidade absoluta ao personagem, estando mais próximos à denominação de cospobre - conforme relatou Osmar, ou competir nos desfiles, 
com o cosplay detalhado, concorrendo a premiações significativas, como viagens ao Japão. De igual maneira, estas oposições indicam hierarquias e relações econômicas assimétricas evidenciando quanto é possível gastar para fazer um cosplay e os recursos disponíveis para realizá-lo. O consumo de materialidades também está relacionado ao modo como os cosplayers habitam as memórias de narrativas e personagens geradoras dos cosplays.

\section{Considerações finais}

Esta pesquisa ainda está longe do final, entretanto, é possível apontar, como considerações provisórias, as transformações operadas nos códigos dos textos culturais midiáticos e, de igual modo, os engendramentos das relações cosplayers-cosplays e as formas de habitar memórias de narrativas e de personagens verificadas pelo ato de selecionar as personagens para o cosplay. $\mathrm{O}$ corpo parece ser o objeto privilegiado para estes questionamentos. O corpo e seus tempos.

Na cena cosplay, as temporalidades se invertem: a velocidade como código das narrativas midiáticas audiovisuais voltadas para este público se descompassa no tempo largo da andança sem pressa. Loki, Gata Negra, Link, Super Mario, sobem e descem lances de escada placidamente, à conversa com amigos; refestelam-se nos bancos de cimento. As personagens materializadas criam novas narrativas. As antigas impressas e audiovisuais agora encontram no corpo-mídia primária-multiplataforma do cosplayer seu código. Pelo corpo do cosplayer, avistam-se rastros do que foram nas telas, nas páginas. Pelo corpo, o texto narrativo midiático cresce por si mesmo, transformado pela invenção dos materiais e de outro tempo que o condiciona. Feito de novas materialidades, propulsor de novos sentidos, torna-se, então, texto-memória expandindo-se no espaço semiótico desta cena juvenil. 


\section{Referências Bibliográficas}

AMARAL, Adriana; DUARTE, R. "A Subcultura cosplay no Orkut: comunicação e sociabilidade online e off-line”. In: BORELLI, Sílvia; FREIRE FILHO, João. Culturas juvenis no século XXI. São Paulo: Educ, 2008.

BAITELLOJUNIOR, Norval. A serpente, a maçã e o holograma: esboços para uma Teoria da Mídia. São Paulo: Paulus, 2010.

BARBOSA, Alexandre. "Quadrinhos japoneses: uma perspectiva histórica e ficcional”. In: LUYTEN, Sônia (org.). Cultura Pop Japonesa. São Paulo: Hedra, 2005.

BLUM, Alan. The imaginative structure of the city. Montreal: McGuill-Queen's University Press, 2003.

CANEVACCI, Massimo. Culturas extremas: mutações juvenis nos corpos das metrópoles. Rio de Janeiro: DP\&A, 2005.

COELHO Jr, L.; SILVA, Sara Santos (2007). “Cosplayers como fenômeno psicossocial: do reflexo da cultura de massa ao desejo de ser herói”. Revista Brasileira de Desenvolvimento e Humano, 17(1): 64-75. Disponível em <http://www.revistasusp.sibi.usp.br/ pdf/rbcdh/vl7nl/06.pdf>. Acesso em 25 set. 2012.

FERREIRA, Jerusa Pires. "Cultura é Memória”. In: Revista USP, n.24, mar./mai.1989. São Paulo: USP, CCS, 1989.

FREIRE FILHO, João. Reinvenções da resistência juvenil: os estudos culturais e as micropolíticas do cotidiano. Rio de Janeiro: Mauad, 2007.

HERSCHMANN, Michel et al. "Os steampunks e as inquietações de um mundo retrofuturista." Trabalho apresentado ao GT de Comunicação e Cultura, do XXI ENCONTRO da COMPÓS, realizado na Universidade Federal de Juiz de Fora, Juiz de Fora, de 12 a 15 de junho de 2012. Disponível em <http://www.compos.org.br/biblioteca. php>. Acesso em jan. 2013. 
HOBSBAWM, Eric. Era dos extremos: o breve século XX 19141991. São Paulo: Companhia das Letras, 2009.

JANOTTI, J. "Entrevista - Will Straw e a importância da ideia de cenas musicais nos estudos." In: Revista ECompós. Focando na escuta: som, música e comunicação.Vol. 15, No 2 (2012). Disponível em <http://www.compos.org.br/seer/index.php/ecompos/issue/current>. Acesso em 12 nov. 2012.

LOTMAN, Iuri. "Acerca de la semiosfera." In: La semiosfera I. Madri: Ediciones Cátedra, 1996.

. "La memória de la cultura". In: La semiosfera II. Madri: Ediciones Cátedra, 1998. Tradução nossa.

e Bóris USPENSKII. "Sobre o mecanismo semiótico da cultura". In: Ensaios de Semiótica Soviética. Lisboa, Livros Horizontes, 1981.

LUYTEN, Sônia. (Org.) Cultura pop japonesa - mangá e anime. São Paulo; Hedra, 2005.

MACHADO, Irene. Escola de semiótica. São Paulo: Ateliê Editorial, 2003.

Semiótica da cultura e semiosfera. São Paulo: Annablumme/FAPESP, 2007.

NUNES, M. A memória na mídia: A evolução dos memes de afeto. São Paulo: Annablume/FAPESP, 2001.

"A cena cosplay: vinculações e produção de subjetividade.” In: Revista Famecos. Porto Alegre, v. 20 , n. 2 , pp. $430-445$, maio/ago. 2013

"Consumo musical nas culturas juvenis: cosplay, mundo pop e memória." Revista Contracampo, n.25, dez 2012. Niterói: Contracampo, 2012b. p-80-96.

OKANO, Michiko. “A Imagem do Japão Contemporâneo.” In: Memai. Disponível em <http://www.jornalmemai.com.br/tag/ 
michiko-okano>. Acesso em 18 nov. 2012.

REGUILLO, Rossana. Culturas juveniles: formas políticas del desencanto. Buenos Aires: Siglo Veintiuno Editores, 2012.

ROCHA, Rose de Melo. "Comunicação e consumo: por uma leitura política dos modos de consumir." In: BACCEGA, Maria Aparecida(org.). Comunicação e culturas do consumo. São Paulo: Atlas, 2008.

SCHNAIDERMAN, Bóris (org.). Semiótica russa. São Paulo: Perspectiva, 1979.

SLATER, Don. Cultura do consumo e modernidade. São Paulo: Nobel, 2002.

STRAW, Will. "Cultural Scenes" Loisir et societélsociety and leisure, vol.27, n.2., 2004. Disponível em <http://strawresearch. mcgill.ca/straw/loisirarticle.pdf $>$.

Artigo recebido em novembro de 2013 e aprovado em março de 2014. 